\title{
Análise bioeconômica do farelo de arroz na recria de bezerras de corte em azevém
}

\author{
[Bioeconomics analyses of rice brain use for reaning of beef heifers on Italian ryegrass pasture] \\ L.G. Amaral Neto ${ }^{1}$, L. Pötter ${ }^{2}$, M.G. Rocha ${ }^{2}$ M.F. Silva ${ }^{2}$, J.M. Vicente ${ }^{1}$, \\ P.R. Salvador ${ }^{2}$, M.J.O. Sichonany ${ }^{2}$, V.B. Rosa ${ }^{1}$ \\ ${ }^{1}$ Aluno de pós-graduação - Universidade Federal de Santa Maria - Santa Maria, RS \\ ${ }^{2}$ Universidade Federal de Santa Maria - Santa Maria, RS
}

\begin{abstract}
RESUMO
Objetivou-se avaliar a economicidade, o desempenho produtivo e o desenvolvimento das estruturas corporais relacionadas ao trato reprodutivo de bezerras de corte mantidas exclusivamente em pastagem de azevém (Lolium multiflorum Lam.) ou em pastagem de azevém recebendo 0,5 e 1,0\% do peso corporal (PC) de farelo de arroz integral (FAI) como suplemento. O método de pastejo foi o rotativo, e o intervalo entre pastejos foi estabelecido considerando-se a soma térmica necessária para a emissão de 1,5 folha de azevém $\left(187,5^{\circ} \mathrm{C}\right)$. $\mathrm{O}$ delineamento experimental foi o inteiramente ao acaso, com medidas repetidas no tempo. O ganho médio diário das bezerras não diferiu entre os sistemas alimentares. A taxa de lotação e o ganho de peso por área foram maiores quando as bezerras receberam 1,0\% do PC de farelo de arroz integral. A maior margem bruta foi observada quando as bezerras receberam $0,5 \%$ de FAI. O custo variável obtido para os diferentes sistemas alimentares apresentou comportamento crescente em função dos níveis de FAI, superando o uso exclusivo do azevém em 49,4\% e 81,8\%. O peso corporal final, o escore de condição corporal e o escore do trato reprodutivo não diferiram entre os sistemas alimentares. Considerando-se um animal adulto com peso corporal médio de $450 \mathrm{~kg}$, as bezerras ao início do experimento apresentaram $34 \%$ do peso corporal adulto e peso corporal final médio de $56 \%$ do peso adulto. A utilização de níveis de farelo de arroz integral (FAI) na recria de bezerras de corte sob pastejo rotativo em azevém não modifica o ganho médio diário e o escore do trato reprodutivo. $\mathrm{O}$ fornecimento de $1 \%$ de FAI mostrou efeito substitutivo, proporcionando um incremento de $31,2 \%$ na taxa de lotação e de 38,3\% no ganho por área. O sistema alimentar AZ0,5 permitiu uma maior margem bruta; já o retorno financeiro direto foi positivo em todos os sistemas alimentares, com melhor retorno calculado para o uso exclusivo do azevém.
\end{abstract}

Palavras-chave: ganho por área, Lolium multiflorum Lam. margem bruta, suplemento, taxa de lotação

\begin{abstract}
The experiment was carried out with the objective of evaluating the gross margin, the productive and reproductive performance of beef heifers kept exclusively on ryegrass pasture (Lolium multiflorum Lam.) or ryegrass receiving 0.5 and $1.0 \%$ of body weight $(B W)$ of whole rice bran as supplement. The grazing method was the rotational and the interval between grazings was set by the thermal sum required for the appearing of 1.5 ryegrass leaf $\left(187.5^{\circ} \mathrm{C}\right)$. The experimental design was completely randomized with repeated measures. Heifers average daily gain did not differ between the feeding systems. The stocking rate and weight gain per area were higher when heifers received $1.0 \% \mathrm{BW}$ of whole rice bran. The higher gross margin was observed when heifers received $0.5 \% \mathrm{BW}$. The variable cost obtained for the different feeding systems showed increasing behavior depending on the WRB levels, surpassing the exclusive use of ryegrass in $49.4 \%$ and $81.8 \%$. The final body weight, body condition score and reproductive tract score did not differ between the feeding systems. Considering an adult animal with an average body weight of $450 \mathrm{~kg}$, the heifers at the beginning of the experiment showed $34 \%$ of mature body weight and final average body weight of 56\% of adult weight. The use of rice bran levels (FAZ) in the rearing of beef
\end{abstract}

Recebido em 13 de junho de 2017

Aceito em 2 de julho de 2018

E-mail: luiz.zoot@gmail.com 
heifers under rotational grazing on ryegrass does not change the average daily gain and the reproductive tract score. The supply of 1\% FAI showed substitutive effect, providing an increase in capacity of 31,2\% and $38.3 \%$ rate of the gain per area. The food system AZO,5 allowed a higher gross margin, as the economic return was positive in all food systems, with better return calculated for the exclusive use of ryegrass.

Keywords: weight gain per area, Lolium multiflorum Lam. Gross margin, supplement, stocking rate

\section{INTRODUÇÃO}

O rebanho bovino brasileiro é de aproximadamente 194 milhões de animais, sendo o Rio Grande do Sul (RS) considerado o sétimo produtor de bovinos. Nesse rebanho, $13,7 \%$ são bezerras de corte (Anuário..., 2014). A recria de fêmeas de corte é a fase que pode antecipar a idade ao primeiro acasalamento, o que reduz o intervalo entre gerações e a participação de animais improdutivos na composição do rebanho. Essa fase, no sul do Brasil, é realizada quase exclusivamente em pastagens nativas, nas quais predominam espécies de clima tropical, sendo limitante tanto em quantidade como em qualidade no período de outono/inverno. A utilização de pastagens cultivadas de inverno, como o azevém (Lolium multiflorum Lam.), tem seu uso consolidado no estado, representando uma alternativa para quem busca melhorar o desempenho produtivo na recria de fêmeas de corte.

Entre as alternativas de manejo que podem proporcionar um melhor aproveitamento do pasto e da área estão o método de pastejo e a suplementação energética. Mesmo a literatura mostrando que $66 \%$ dos trabalhos não apontam diferença entre os métodos (Briske et al., 2008), o método de pastejo rotativo pode elevar a taxa de lotação, aumentando, assim, a frequência de desfolha. O uso da morfogênese como critério de manejo possibilita tomar decisões adequadas ao manejar as pastagens, assim como definir o momento mais adequado para a entrada e saída dos animais nos piquetes, a intensidade do pastejo e a duração do período de descanso da pastagem.

A utilização de subprodutos é uma alternativa para suplemento energético, destacando-se o farelo de arroz integral (FAI) pela sua abundância no RS. O FAI é um subproduto do beneficiamento do arroz e representa cerca de 8$10 \%$ do resíduo gerado do grão com casca (Gonçalves et al., 2007).
Respostas anteriores, obtidas com o uso do FAI na recria de bezerras de corte em pastagem de inverno, mostram que, quando associado à polpa cítrica (1:1), esse subproduto proporcionou incrementos de $22 \%$ no ganho médio diário e de $46 \%$ na taxa de lotação, em relação ao uso exclusivo da pastagem (Frizzo et al., 2003). Eloy et al. (2014) concluíram que a utilização de 0,8\% do peso corporal (PC) de FAI não modificou a ingestão do pasto das novilhas, não alterando, portanto, a taxa de lotação.

Dados referentes a níveis de FAI associado ao método de pastejo rotativo são escassos ou inexistentes. $\mathrm{O}$ presente estudo tem como objetivo avaliar o desempenho produtivo e o reprodutivo de bezerras de corte mantidas exclusivamente em pastagem de azevém (Lolium multiflorum Lam.) ou recebendo diferentes níveis de farelo de arroz integral como suplemento energético, sob método de pastejo rotativo.

\section{MATERIAL E MÉTODOS}

O experimento foi desenvolvido em área do Departamento de Zootecnia da Universidade Federal de Santa Maria, localizado na região fisiográfica denominada Depressão Central, coordenadas $29^{\circ} 43^{\prime} \mathrm{S}, 53^{\circ} 42^{\prime} \mathrm{W}$, com altitude de $95 \mathrm{~m}$ acima do nível do mar. As avaliações de campo foram realizadas no período de 10/07 a 23/10/2014. O clima da região é Cfa, subtropical úmido, segundo a classificação de Köppen (Moreno, 1961). O solo é classificado como Argissolo vermelho distrófico arênico (Sistema..., 1999). Os dados meteorológicos referentes aos meses que compreenderam o período experimental foram obtidos junto à Estação Meteorológica da Universidade Federal de Santa Maria, utilizando-se as médias históricas dos últimos 30 anos para a temperatura média.

Os sistemas alimentares foram constituídos de bezerras de corte em pastagem de azevém (Lolium multiflorum Lam.) recebendo farelo de 
arroz integral (FAI) como suplemento energético: 0,0 (AZ); 0,5 (AZ0,5) e 1,0\% (AZ1) do peso corporal (PC), sob método de pastejo rotativo. $\mathrm{O}$ suplemento era fornecido diariamente às 14 horas. Foi adicionado calcário calcítico ao farelo de arroz, na proporção de $4 \%$. A composição química do FAI foi: $89,7 \%$ de matéria seca (MS); 14,2\% de proteína bruta (PB); $14,7 \%$ de extrato etéreo (EE); $72,3 \%$ de nutrientes digestíveis totais (NDT) e $27,3 \%$ de fibra em detergente neutro (FDN). A área experimental utilizada correspondeu a 4,8 hectares, dividida em seis piquetes de 0,8 hectare cada, os quais constituíram as unidades experimentais. Cada piquete foi dividido em cinco parcelas de 0,16ha. Foi utilizada uma área anexa de 3,5 hectares para manter os animais reguladores da massa de forragem. A pastagem de azevém foi estabelecida em $08 / 05 / 2014$, por meio de duas gradagens (aradora e niveladora), utilizando-se $45 \mathrm{~kg} \mathrm{ha}^{-1}$ de sementes, semeadas a lanço. Para a adubação de base, foram aplicados $250 \mathrm{~kg} \mathrm{ha}^{-1}$ de NPK (5-20-20). A adubação nitrogenada $(\mathrm{N})$, na forma de ureia, aplicada em cobertura, totalizou $110 \mathrm{~kg} \mathrm{ha}^{-1}$ de $\mathrm{N}$, fracionada em duas aplicações. A primeira foi realizada em 11/06/2014, após a emissão do segundo perfilho, e a segunda a partir do dia 02/08/2014 (início do segundo ciclo), imediatamente após a saída dos animais de cada parcela.

Foram utilizadas 40 bezerras da raça Angus, com idade média inicial de oito meses e $155 \pm 28 \mathrm{~kg}$ de PC, sendo alocadas três bezerras-teste em cada unidade. $\mathrm{O}$ método de pastejo utilizado foi o rotativo, com número variável de animais, com sucessivos períodos de ocupação e descanso. A taxa de lotação foi ajustada de acordo com metodologia descrita por Heringer e Carvalho (2002), em que eram ofertados aos animais 50\% da massa de forragem de entrada (intensidade de pastejo de 50\%), mantendo-se uma altura de saída de 10 a $12 \mathrm{~cm}$. O período de descanso foi estabelecido pela soma térmica de $187,5^{\circ} \mathrm{D}$, equivalente à soma térmica necessária para a emissão de 1,5 folha do azevém, considerando-se o filocrono de $125^{\circ} \mathrm{D}$ (Confortin et al., 2010). Os três primeiros ciclos foram de 20 dias (16 dias de descanso e quatro dias de ocupação) e os três ciclos finais foram de 15 dias (12 dias de descanso e três dias de ocupação) em cada sistema alimentar.
A massa de forragem média (MF; $\mathrm{kg} \mathrm{ha}^{-1}$ de MS) foi estimada, em cada ciclo de pastejo, por dois cortes, em locais representativos da altura média do dossel, utilizando-se um quadro de $0,250 \mathrm{~m}^{2}$, no momento de entrada e saída dos animais da parcela. O teor de MS foi determinado por secagem das amostras em estufa a $55^{\circ} \mathrm{C}$, por 72 horas. A altura do dossel foi medida em 20 pontos dentro da parcela. A massa de forragem inicial foi de $1600 \mathrm{~kg} \mathrm{ha}^{-1}$ de MS.

A simulação de pastejo foi realizada de acordo com metodologia descrita por Euclides e Macedo e Macedo (1992), um dia antes da retirada dos animais das parcelas. As amostras de forragem foram levadas à estufa a $55^{\circ} \mathrm{C}$, por 72 horas, e moídas em moinho do tipo "Willey" para posteriores análises laboratoriais. $\mathrm{O}$ teor de matéria seca das amostras foi determinado por secagem em estufa a $105^{\circ} \mathrm{C}$, durante pelo menos oito horas. O conteúdo de cinzas foi determinado por combustão a $600^{\circ} \mathrm{C}$, durante quatro horas, e a matéria orgânica foi obtida por diferença de massa. O nitrogênio total foi determinado pelo método Kjeldahl (Official..., 1997). A análise de fibra em detergente neutro foi realizada conforme Senger et al. (2008). A digestibilidade in situ da matéria seca da forragem e do suplemento foi determinada por meio da incubação por 48 horas no rúmen de um bovino fistulado (Demarquilly 1969). O teor de extrato etéreo do farelo de arroz foi determinado de acordo com Bligh e Dyer (1959). O teor de nutrientes digestíveis totais (NDT) foi calculado segundo Kunkle e Bates (1998).

As pesagens foram realizadas no início e no fim do período de avaliação da pastagem, respeitando-se um jejum de sólidos e líquidos por 12 horas. Também foram realizadas pesagens ao final de cada ciclo de pastejo para posterior cálculo da taxa de lotação. Por ocasião das pesagens, inicial e final, as bezerras foram submetidas à avaliação subjetiva do escore de condição corporal, considerando-se o escore de condição de 1 (muito magro) a 5 (muito gordo). $\mathrm{O}$ ganho médio diário foi obtido pela diferença de peso das bezerras-testes entre as pesagens inicial e final, dividida pelo número de dias de avaliação.

A taxa de lotação $\left(\mathrm{kg} \mathrm{ha}^{-1}\right.$ de PC) foi obtida pela soma do peso médio das bezerras-testes acrescida da soma do peso médio das bezerras 
reguladoras da massa de forragem, multiplicada pelo número de dias em que foram mantidas no piquete e dividida pelo número de dias do período experimental. O ganho de peso corporal (PC) por hectare foi calculado pelo quociente entre a taxa de lotação média do piquete pelo peso médio das bezerras-teste em cada piquete, obtendo-se o número médio de bezerras por hectare. Multiplicando-se esse valor pelo ganho médio diário das bezerras-testes e pelo número de dias de pastejo, foi estimada a produção de peso corporal por hectare $\left(\mathrm{kg} \mathrm{ha}^{-1} \mathrm{de} \mathrm{PC}\right)$.

O escore de trato reprodutivo foi avaliado no dia 23/10/2014. Foi utilizada a metodologia descrita por Anderson et al. (1991), sendo as novilhas agrupadas em categorias, conforme o ETR, em púberes $(\mathrm{ETR}=4$ ou 5$)$, pré-púberes $(\mathrm{ETR}=3)$ e infantis $(\mathrm{ETR}=1$ ou 2$)$. Na mesma ocasião da avaliação de ETR, foi realizada a ultrassonografia, com a finalidade de medir o diâmetro folicular e verificar a presença de corpo lúteo. A medida de diâmetro folicular serviu como referência para estratificar as novilhas de acordo com o tamanho do folículo em: ETR 1 ausência de folículos; ETR 2 - folículo até $8 \mathrm{~mm}$; ETR 3 - folículo entre 8 e 10mm; ETR 4 folículo maior que $10 \mathrm{~mm}$; e ETR 5 - folículo maior que $10 \mathrm{~mm}$ com presença de corpo lúteo.

A avaliação econômica dos sistemas alimentares foi realizada com a utilização de planilhas de cálculo do Microsoft Excel®, versão 2013, segundo modelo proposto por Pötter et al. (2000). Os preços utilizados para o cálculo dos custos variáveis, bem como para a conversão dos valores para $\mathrm{kg}$ de $\mathrm{PC}$ de novilha, foram obtidos com base em uma pesquisa de mercado efetuada em junho de 2017, na região de Santa Maria, RS. Foram consideradas, para o cálculo de cada sistema alimentar, as despesas com arrendamento, estabelecimento da pastagem, subdivisão dos piquetes, vermífugo, mineralização e suplemento. $\mathrm{O}$ custo da mão de obra foi estabelecido com base no salário mínimo rural do estado, somado aos encargos sociais. Considerou-se um total de 220 horas mensais de trabalho (Pötter et al., 2000). Para os custos de hora-trator, foram somados os gastos de depreciação, conservação, combustíveis, lubrificantes e mão de obra, e, para os implementos, foram computados os custos de depreciação e conservação. A receita bruta (RB) foi obtida do ganho de peso por área multiplicado pelo preço do $\mathrm{kg}$ da novilha. Da relação receita bruta $(\mathrm{RB}) /$ custo variável $(\mathrm{CV})$, obteve-se o retorno financeiro direto (RFD) por sistema alimentar. A margem bruta (MB) de cada operação foi obtida pela diferença entre RB e CV.

O delineamento experimental foi o inteiramente ao acaso, com medidas repetidas no tempo, com três tratamentos (sistemas alimentares) e duas repetições de área. Para se compararem os sistemas alimentares, as variáveis que apresentaram normalidade foram submetidas à análise de variância pelo procedimento Mixed do programa estatístico SAS ${ }$, considerando-se o efeito fixo de sistema alimentar, os ciclos de pastejo e suas interações e os efeitos aleatórios do resíduo e de piquetes aninhados nos sistemas alimentares.

As médias, quando verificadas diferenças, foram comparadas pelo procedimento lsmeans. A interação entre tratamentos e ciclos de pastejo foi desdobrada quando significativa a $5 \%$ de probabilidade. As variáveis coletadas apenas no início e no fim do experimento foram avaliadas seguindo a estrutura de um delineamento inteiramente ao acaso, com três tratamentos e duas repetições de área. As variáveis que não apresentaram normalidade foram submetidas ao teste de Kruskal-Wallis.

\section{RESULTADOS E DISCUSSÃO}

O período de utilização da pastagem de azevém foi de 105 dias, de 10/07/2014 a 23/10/2014. Não houve interação entre sistemas alimentares e períodos de avaliação para as variáveis do pasto $(\mathrm{P}>0,05)$. As bezerras, nos diferentes sistemas alimentares, foram mantidas em similar massa de foragem $\left(1973,7 \pm 435,1 \mathrm{~kg} \mathrm{ha}^{-1}\right.$ de MS). A altura de saída dos piquetes não diferiu $(11,5 \pm 0,7 \mathrm{~cm})$, proporcionando semelhante manejo do pasto entre os sistemas alimentares. Os valores médios obtidos na forragem da simulação de pastejo foram de $17,8 \pm 3,3 \%$ de proteína bruta (PB), $50,2 \pm 7,4 \%$ de fibra em detergente neutro (FDN), $79,1 \pm 11,4 \%$ de digestibilidade in situ da matéria seca (DISMS) e $72,1 \pm 9,1 \%$ de nutrientes digestíveis totais (NDT), independentemente do sistema alimentar.

A massa de forragem ficou acima do recomendado por Roman et al. (2007), entre 
1100 e $1800 \mathrm{~kg} \mathrm{ha}^{-1}$ em pastejo contínuo, em que existe similar eficiência de transformação da forragem em produto animal. Esse valor acima do recomendado pode ser explicado pelo manejo adotado no método de pastejo rotativo, em que foi utilizada uma intensidade de pastejo de $50 \%$, mantendo-se uma altura de saída dos piquetes entre 10 e $12 \mathrm{~cm}$. Segundo Carvalho et al. (2001), quando o azevém é manejado abaixo de $10 \mathrm{~cm}$, há restrição no consumo de forragem. Os níveis de $\mathrm{PB}$ foram 1,3 vez superiores à exigência para essa categoria, que é de 13,5\% (Nutrient..., 2000). Os teores de FDN ficaram abaixo de 55\%, considerado como limitante ao consumo (Van Soest, 1994).

O ganho médio diário (GMD) das bezerras não diferiu entre os sistemas alimentares, com média de $948 \pm 0,1 \mathrm{~g} \mathrm{dia}{ }^{-1}$ (Tab. 1). Esse resultado evidencia o efeito substitutivo do farelo de arroz integral. Quando a disponibilidade de forragem é alta, como no presente trabalho, o fornecimento de suplemento energético pode aumentar o consumo total, mas pode diminuir a ingestão de forragem e, em geral, é quando as maiores taxas de substituição são verificadas (Bargo et al., 2003). Os bovinos reduzem o consumo de forragem quando a relação NDT:PB é menor que 7,0 e quando o NDT proveniente do suplemento é maior que $0,70 \%$ do PC (Moore et al., 1999). No sistema alimentar AZ1, a relação NDT:PB foi de 4,05 e o NDT proveniente do suplemento foi de $0,72 \%$ do PC, confirmando o efeito de substituição. Esse efeito substitutivo pode ser considerado positivo, pois oferece a oportunidade que um maior número de animais receba a mesma dieta numa mesma área, permitindo também manter a taxa de lotação no decorrer do ciclo da pastagem, mesmo em períodos de menor crescimento do pasto (Fernandes e Mieres, 2005). O GMD observado nessa fase de recria, em todos os sistemas alimentares, esteve acima do intervalo entre 400 e $800 \mathrm{~g} \mathrm{dia}^{-1}$, considerado por Beretta e Lobato (1998) como necessário para que seja atingida, o mais cedo possível, a maturidade sexual das fêmeas de corte. Ao contrário, o efeito aditivo ocorre quando a forragem possui uma baixa concentração de um ou mais nutrientes limitantes para os microrganismos do rúmen, por exemplo, o nitrogênio (Dixon e Stockdale, 1999). Gonçalves et al. (2007), ao trabalharem com novilhos em pastagem natural recebendo níveis de farelo de arroz, relataram um incremento no GMD de $60 \%$ nos níveis 0,5 e $1,5 \%$ do PC desses novilhos quando comparados com animais não suplementados, com uma relação NDT: PB de 8,0 para o campo nativo. Eloy et al. (2014), ao avaliarem novilhas de corte em pastagem exclusiva de azevém ou recebendo $0,8 \%$ do PC de FAI com e sem adição de ionóforo, relataram ganho médio diário adicional de 250 gramas proporcionado pela utilização de ionóforo.

Tabela 1. Parâmetros de desempenho e medidas corporais de bezerras de corte recebendo níveis de farelo de arroz em pastagem de azevém

\begin{tabular}{|c|c|c|c|c|c|}
\hline \multirow{2}{*}{ Variáveis } & \multicolumn{3}{|c|}{ Sistemas alimentares } & \multirow{2}{*}{$\mathrm{DP}^{4}$} & \multirow{2}{*}{$\mathrm{P}^{5}$} \\
\hline & $\mathrm{AZ}^{1}$ & $\mathrm{AZO}, 5^{2}$ & $\mathrm{AZ} 1,0^{3}$ & & \\
\hline Ganho médio diário, $\mathrm{g}$ & $910 \mathrm{a}$ & $1007 \mathrm{a}$ & $927 \mathrm{a}$ & 0,1 & 0,8349 \\
\hline Taxa de lotação, $\mathrm{kg} \mathrm{ha}^{-1}$ & $1362,1 \mathrm{~b}$ & $1622,5 \mathrm{ab}$ & $1786,8 \mathrm{a}$ & 209,4 & 0,0303 \\
\hline Ganho de peso por área, $\mathrm{kg} \mathrm{ha}^{-1}$ & $623,1 \mathrm{~b}$ & $810,7 \mathrm{a}$ & $862,0 \mathrm{a}$ & 0,9 & 0,0562 \\
\hline ETR $^{6}$ & $1,9 \mathrm{a}$ & $2,0 \mathrm{a}$ & $2,1 \mathrm{a}$ & 0,4 & 0,5553 \\
\hline $\mathrm{PCI}^{7}, \mathrm{~kg}$ & $159,6 \mathrm{a}$ & $152,4 \mathrm{a}$ & $153,2 \mathrm{a}$ & 8,2 & 0.2728 \\
\hline $\mathrm{PCF}^{8}, \mathrm{~kg}$ & $255,2 \mathrm{a}$ & $258,2 \mathrm{a}$ & $250,7 \mathrm{a}$ & 22,2 & 0,8574 \\
\hline $\mathrm{ECCF}^{9}$ & $3,5 \mathrm{a}$ & $3,6 \mathrm{a}$ & $3,5 \mathrm{a}$ & 0,2 & 0,9262 \\
\hline
\end{tabular}

${ }^{1}$ Bezerras exclusivamente em azevém; ${ }^{2}$ bezerras em azevém recebendo $0,5 \%$ do peso corporal (PC) de farelo de arroz integral; ${ }^{3}$ bezerras em azevém recebendo $1 \%$ do PC de farelo de arroz integral; ${ }^{4}$ desvio-padrão; ${ }^{5}$ probabilidade entre sistema alimentares; ${ }^{6}$ escore do trato reprodutivo; ${ }^{8}$ peso corporal final; ${ }^{9}$ escore de condição corporal final.

A taxa de lotação diferiu entre os sistemas alimentares $(\mathrm{P}<0,05$; Tab. 1). A maior taxa de lotação foi observada nos piquetes em que as bezerras receberam $1,0 \%$ do PC de FAI em comparação aos piquetes em que as bezerras permaneceram exclusivamente em azevém $\left(1362,1 \pm 209,4 \mathrm{~kg} \mathrm{ha}^{-1} \mathrm{PC}\right)$. O fornecimento de $0,5 \%$ do PC de FAI permitiu a obtenção de taxa de lotação intermediária entre os demais sistemas alimentares (Tab. 1). Esse resultado confirma a hipótese do efeito substitutivo do consumo do pasto pelo suplemento. $\mathrm{O}$ fornecimento de $1 \%$ do 
PC de FAI permitiu um incremento de $31,2 \%$ na taxa de lotação, o que equivale a $424,7 \mathrm{~kg} \mathrm{ha}^{-1}$ de PC ou duas bezerras com peso corporal médio de $212 \mathrm{~kg}$ a mais por hectare. Para se manter a mesma taxa de lotação do sistema AZ1 no sistema AZ, seria necessário um acréscimo de área de 0,3 hectare. $\mathrm{O}$ ganho de peso por área (GPA) diferiu entre os sistemas alimentares $(\mathrm{P}<0,10$; Tab. 1). O maior ganho de peso por área foi obtido no sistema AZ1 $(862,0 \pm 0,9 \mathrm{~kg}$ ha ${ }^{1}$ ), sendo $38,3 \%$ superior quando comparado ao sistema $\mathrm{AZ}$, o que equivale a uma produção de $238,9 \mathrm{~kg}$ de PC a mais por hectare. O GPA no sistema AZ0,5 $\left(810,7 \pm 0,9 \mathrm{~kg} \quad \mathrm{ha}^{-1}\right)$ foi intermediário. Frizzo et al. (2003), ao trabalharem com bezerras em pastagem de aveia e azevém recebendo polpa cítrica mais farelo de arroz (1:1) como suplemento, com nível de suplemento de $0,7 \%$ do PC, obtiveram um aumento na taxa de lotação de $26 \%$, e quando foi fornecido $1,4 \%$ do PC de suplemento, o incremento na taxa de lotação foi de $76 \%$ em relação ao sistema alimentar exclusivo a pasto. Já Eloy et al. (2014) não observaram modificações na ingestão do pasto por bezerras de corte em azevém recebendo FAI como suplemento, o que resultou em taxa de lotação semelhante, independentemente do fornecimento de suplemento.

O escore do trato reprodutivo (ETR) não diferiu entre os sistemas alimentares, com média de $2 \pm 0,4$ ( $\mathrm{P}>0,05$; Tab. 1). O resultado obtido considera as bezerras com escore infantil conforme a metodologia descrita por Anderson et al. (1991). Para sistemas de acasalamentos em idades mais precoces, como aos 14 meses de idade, a bezerra deve ter cerca de $40 \%$ do peso adulto ao desmame e chegar a $65 \%$ do peso adulto no acasalamento (Rocha e Lobato, 2002). Considerando um animal adulto com peso corporal médio de $450 \mathrm{~kg}$, as bezerras, no início do experimento, apresentaram $34 \%$ do peso corporal adulto $(155,1 \pm 8,2 \mathrm{~kg}$ de PC; Tab. 1$)$, e o peso corporal final médio de $56 \%$ do peso adulto $(254,7 \pm 22,2 \mathrm{~kg}$; Tab. 1) não foi suficiente para que elas atingissem a puberdade. Esse resultado difere do relatado por Funston et al. (2012), em pesquisas recentes, que indicam sistemas nos quais as bezerras são recriadas para atingirem um menor peso 'alvo', entre 50 e $57 \%$ do PC para o primeiro acasalamento, e se mostram mais produtivas em comparação às bezerras recriadas para atingirem o tradicional PC 'alvo', de $65 \%$ do PC. Conforme esses autores, essa mudança no peso à puberdade está relacionada com alterações genéticas recentes para reduzir idade à puberdade de bovinos de corte. Bezerras com menor pesoalvo para o acasalamento têm maior rentabilidade durante sua vida produtiva devido aos menores custos com alimentação. Essas condições indicam que as bezerras não estão aptas para o acasalamento aos 14 meses de idade, mesmo com o escore de condição corporal (ECC) médio de 3,6 $\pm 0,2$ (Tab. 1), superior a 3, numa escala de 1 a 5, sugerido por Rocha (1997) como determinante para o início das funções reprodutivas em fêmeas bovinas. A semelhança entre o ECC pode ser explicada pela semelhança no GMD entre os sistemas alimentares. Segundo Rocha et al. (2003), a velocidade de ganho de peso é um dos fatores determinantes de maior ou menor deposição de gordura.

O resumo da atividade econômica calculada para os sistemas alimentares está detalhado na Tab. 2. A soma dos gastos com preparo do solo, semeadura e adubação ( $P, \quad K$ e $N)$, que representam o custo com o estabelecimento do azevém, totaliza $\mathrm{R} \$ 1141,2$, representando 71,4; 45,6 e 39,3\% do custo variável dos sistemas AZ, AZ0,5 e AZ1, respectivamente. O sistema alimentar AZ0,5 permitiu maior margem bruta, superando em R\$227,7 e R\$ 194,3 o valor da margem bruta dos sistemas alimentares AZ e AZ1, respectivamente. Em avaliação de diferentes sistemas alimentares com utilização de pastagem hibernal para bezerras de corte, com ou sem adição de suplementos, Pilau et al. (2003) obtiveram margens brutas que variaram de $\mathrm{R} \$$ 50,00 a R \$ 148,00 ha ${ }^{-1}$, justificadas pelo elevado custo do suplemento. O custo variável obtido para os diferentes sistemas alimentares apresentou comportamento crescente em função dos níveis de FAI, superando o uso exclusivo do azevém em $49,4 \%$ e $81,8 \%$.

O retorno financeiro direto foi positivo em todos os sistemas alimentares, com melhor retorno calculado para o uso exclusivo do azevém. O retorno, mesmo que inferior mas positivo, justifica-se pelo uso do suplemento, pois os custos que envolvem essa prática representam 32,8 e 44,6\% do custo variável para os sistemas alimentares AZ0,5 e AZ1, respectivamente. De acordo com Pilau et al. (2003), a suplementação de bezerras de corte somente será potencializada economicamente quando forem utilizados 
suplementos de baixo custo, o que foi observado no presente trabalho pelo uso do FAI. Além da maior margem bruta observada com o uso do FAI, a liberação de área para outras categorias, decorrência dos incrementos na taxa de lotação, é um dos fatores determinantes na escolha do sistema alimentar a ser empregado.

Tabela 2. Resumo da análise econômica da utilização de níveis de farelo de arroz integral para bezerras de corte sob pastejo rotativo em azevém

\begin{tabular}{cccc}
\hline & \multicolumn{3}{c}{ Sistemas alimentares } \\
\cline { 2 - 4 } Parâmetros econômicos & $\mathrm{AZ}^{1}$ & $\mathrm{AZ0,5^{2 }}$ & $\mathrm{AZ1,0^{3 }}$ \\
& $\mathrm{R} \$$ ha $^{-1}$ & 972,7 & 972,7 \\
\hline Custo da pastagem & 972,7 & 200,0 & 200,0 \\
Arrendamento & 200,0 & 21,3 & 23,4 \\
Vermífugo & 17,9 & 13,3 & 14,6 \\
Sal mineral & 11,2 & 159,6 & 159,6 \\
Cerca elétrica & 159,6 & 353,7 & 779,0 \\
Suplemento & 0 & 116,1 & 127,8 \\
Cochos & 0 & 197,5 & 197,5 \\
Mão de obra suplemento & 0 & 2034,1 & 2474,7 \\
Custo variável & 1361,3 & 3891,3 & 4137,6 \\
Receita bruta & 2990,9 & 1857,2 & 1662,9 \\
Margem bruta & 1629,5 & 1,9 & 1,7 \\
Retorno financeiro direto & 2,2 & $0,5 \%$ & peso corp
\end{tabular}

${ }^{1}$ Bezerras exclusivamente em azevém; ${ }^{2}$ bezerras em azevém recebendo $0,5 \%$ do peso corporal (PC) de farelo de arroz integral; ${ }^{3}$ bezerras em azevém recebendo $1 \%$ do PC de farelo de arroz integral.

$* \mathrm{~kg}$ de peso corporal da bezerra $=\mathrm{R} \$ 4,80$.

No presente trabalho, ficou evidenciado que o uso do FAI como suplemento pode possibilitar que um maior número de bezerras chegue ao final do primeiro inverno com desenvolvimento satisfatório, aspecto relevante no manejo da recria de fêmeas de corte, reduzindo-se, assim, a necessidade de ganho médio diário posterior de até $210 \mathrm{~g} \mathrm{dia}^{-1}$ para o acasalamento aos 18 meses de idade e de $105 \mathrm{~g} \mathrm{dia}^{-1}$ para o acasalamento aos 24 meses de idade, para um peso-alvo para o acasalamento de $292,5 \mathrm{~kg}$, o que torna, qualquer que seja o objetivo, possível de ser alcançado.

\section{CONCLUSÕES}

A utilização de níveis de farelo de arroz integral (FAI) na recria de bezerras de corte sob pastejo rotativo em azevém não modifica o ganho médio diário e o escore do trato reprodutivo. O fornecimento de $1 \%$ de FAI mostrou efeito substitutivo, proporcionando um incremento de $31 \%$ na taxa de lotação e de $38,3 \%$ no ganho por área. O sistema alimentar AZ0,5 permitiu uma maior margem bruta, $\mathrm{R} \$ 1857,2$ por hectare; já o retorno financeiro direto foi positivo em todos os sistemas alimentares, com melhor retorno calculado para o uso exclusivo do azevém.

\section{REFERÊNCIAS}

ANDERSON, K.J; LeFEVER D.G.; BRINKS J.S.; ODDE K.G. The use of reproductive tract scoring in beef heifers. Agri Practice, 1991. Disponível em: < http://agris.fao.org/agris-

search/search.do?recordID=US19930078152>

Acessado em: 25 mai. 2017.

ANUÁRIO DA PECUÁRIA BRASILEIRA. São Paulo: Instituto FNP, 360p. 2014.

BARGO, F.; MULLER, L.D.; KOLVER, E.S.; DELAHOY, J.E. Invited review: production and digestion of supplemented dairy cows on pasture. $J$. Dairy Sci., v.86, p.1-42, 2003.

BERETTA, V.; LOBATO, J.F.P. Sistema" um ano" de produção de carne: avaliação de estratégias alternativas de alimentação hibernal de novilhas de reposição. Rev. Bras. Zootec., v.27, p.157-163, 1998.

BLIGH, E.G.; DYER, W.J. A rapid method of total lipid extraction and purification. Can. J. Biochem. Physiol., v.37, p.911-917, 1959.

BRISKE D.D.; DERNER J.D.; BROWN J.R. et al. Rotational grazing on rangelands: reconciliation of perception and experimental evidence. Rangeland Ecol. Manag., v.61, p.3-17, 2008. 
CARVALHO, P.C.F.; PONTES, L.S.; SILVEIRA, E.O. et al. Sheep performance in Italian ryegrass swards at contrasting sward heights. In: INTERNATIONAL GRASSLAND CONGRESS, 19., 2001, Piracicaba. Proceedings... Piracicaba: FEALQ, 2001. p.845-846.

CONFORTIN, A.C.C.; QUADROS, F.L.F.; ROCHA, M.G. et al. Morfogênese e estrutura de azevém anual submetido a três intensidade de pastejo. Acta Sci. Anim. Sci., v.32, p.385-391, 2010.

DEMARQUILLY, C. Valeur alimentaire du maïs fourrage. I. Composition chimique et digestibilité du maïs sur pied. Ann. Zootec., v.18, p.17-32, 1969.

DIXON, R.M.; STOCKDALE, C.R. Associative effects between forages and grains: consequences for feed utilization. Aust. J. Agricultural Res., v.50, p.757773, 1999.

ELOY, R.L.; ROCHA M.G.; PÖTTER, L. et al. Consumo de forragem por novilhas de corte recebendo farelo de arroz com e sem ionóforo. Ciênc. Rural, v.44, p.1223-1228, 2014.

EUCLIDES, V.P.B.; MACEDO, M.C.M. Avaliação de diferentes métodos de amostragem para estimar o valor nutritivo de forragens sob pastejo. Rev. Bras. Zootec., v.21, p.691-701, 1992.

FERNÁNDEZ, E.; MIERES, J. Algunos conceptos sobre el uso de suplementos en los sistemas invernadores. In: JORNADA PRODUCCION ANIMAL INTENSIVA, 2005, Colonia. Anales... Colonia: INIA La Estanzuela, 2005. p.1-10. (Serie de Actividades de Difusión, n.406).

FRIZZO, A.; ROCHA, M.D.; RESTLE, J. et al. Suplementação energética na recria de bezerras de corte mantidas em pastagem de inverno. Rev. Bras. Zootec., v.32, p.643-652, 2003.

FUNSTON, R.N.; MARTIN, J.L.; LARSON, D.M.; ROBERTS, A.J. Physiology and endocrinology symposium: nutritional aspects of developing replacement heifers. J. Anim. Sci., v.90, p.1166-1171, 2012.

GONÇALVES, M.B.F.; PRATES, E.R.; SILVA, A.C.F. et al. Desempenho de novilhos de corte em pastagem nativa com níveis de suplementação de farelo de arroz integral. Ciênc. Rural, v.37, p.476-481, 2007.

HERINGER, I.; CARVALHO, P.C.F. Ajuste de carga animal em experimentos de pastejo: uma nova proposta. Ciênc. Rural, v.32, p.675-679, 2002.

KUNKLE, W.E.; BATES, D.B. Evaluating feed purchasing options: energy, protein, and mineral supplements. Florida Beef Cattle Short Course, n.1998, p.59-70, 1998.
MOORE, J.E., BRANT, M.H., KUNKLE, W.E., HOPKINS, D.I. Effects of supplementation on voluntary forage intake, diet digestibility, and animal performance. J. Anim. Sci., v.77, p.122, 1999.

MORENO, J.A. Clima do Rio Grande do Sul. Porto Alegre: Secretaria da Agricultura, 1961. 41p.

NUTRIENT requeriment of beef cattle. Washington: NRC, 2000. 249p.

OFFICIAL methods of analysis.16.ed. Gaithersburg, MD: AOAC, 1997. (Método 984.13).

PILAU, A.; ROCHA, M.G.; SANTOS, D.T. Análise econômica de sistemas de

POTTER, L.; LOBATO, J.F.; MIELTZ NETTO, C.G. Análises econômicas de modelos de produção com novilhas de corte primíparas aos dois, três e quatro anos de idade. Rev. Bras. Zootec., v.29, p.861-870, 2000 .

produção para recria de bezerras de corte. Rev. Bras. Zootec., v.32, p.966-976, 2003.

ROCHA, M.G. Desenvolvimento e características de produção de novilhas de corte primíparas aos dois anos de idade. 1997. 247f. Tese (Doutorado em Zootecnia) - Universidade Federal do Rio Grande do Sul, Porto Alegre, RS.

ROCHA, M.G.; LOBATO, J.F.P. Sistemas de alimentação pós desmama de bezerras de corte para acasalamento com 14/15 meses de idade. Rev. Bras. Zootec., v.31, p.1814-1822, 2002.

ROCHA, M.G.; RESTLE, J.; PILAU, A.; SANTOS, D.T. Produção animal e retorno econômico da suplementação em pastagem de aveia e azevém. Ciênc. Rural, v.33, p.573-578, 2003.

ROMAN, J.; ROCHA, M.G.; PIRES, C.C. et al. Comportamento ingestivo e desempenho de ovinos em pastagem de azevém anual (Lolium multiflorum Lam.) com diferentes massas de forragem. Rev. Bras. Zootec., v.36, p.780-788, 2007.

SENGER, C.C.D.; KOZLOSKI, G.V.; SANCHEZ, L.M.B. et al. Evaluation of autoclave procedures for fibre analysis in forage and concentrate feedstuffs. Anim. Feed Sci. Technol., v.146, p.169-174. 2008.

SISTEMA brasileiro de classificação de solos. Brasília: Embrapa, serviço de produção de informação, 1999. 412p.

SOLLENBERGER, L.E.; AGOURIDIS, C.T.; VANZANT, E.S. et al. Prescribed Grazing on Pasturelands. In: JERRY, N.C. Conservation outcomes from pastureland and hayland practices. Lawrence: Allen Press, 2012. cap.3, p.111-204.

VAN SOEST, P.J. Nutritional ecology of the ruminant. 2.ed. Ithaca, New York: Cornell University Press, 1994. 476p. 